\title{
Cerium-Based Sealing Treatment of Mg-Al Hydrotalcite Film on AZ91D Magnesium Alloy
}

\author{
Qiang-Sheng Dong ${ }^{1,2} \cdot$ Zhi-Xin Ba $^{1,2} \cdot$ Zhang-Zhong Wang $^{1,2} \cdot$ Juan Kuang $^{1} \cdot$ Zheng-Yang Cai $^{1} \cdot$ Chen Yuan $^{1}$
}

Received: 31 March 2016/Revised: 20 April 2016/Published online: 27 June 2016

(C) The Chinese Society for Metals and Springer-Verlag Berlin Heidelberg 2016

\begin{abstract}
An environment-friendly cerium-based sealing treatment was developed to improve the surface integrity and corrosion resistance of $\mathrm{Mg}-\mathrm{Al}$ hydrotalcite film on AZ91D magnesium alloy. The cerium dioxide was generated through three stages namely nucleation, growth and dissolution, modifying the surface of AZ91D Mg alloy, and the hydrotalcite film became integral after being treated for $30 \mathrm{~min}$. The results of polarization curves showed that the anti-corrosive performance of the hydrotalcite film was enhanced by the sealing treatment. Moreover, the immersion tests and electrochemical impedance spectrum measurements also demonstrated that the sealed hydrotalcite film provided a longer-term protection of magnesium alloy from corrosion as compared to the unsealed one.
\end{abstract}

KEY WORDS: AZ91D magnesium alloy; Mg-Al hydrotalcite film; Sealing treatment; Ce-containing solution; Corrosion resistance

\section{Introduction}

Magnesium ( $\mathrm{Mg}$ ) alloys have been widely used as typical lightweight materials in the automotive, aeronautic and recreational industries due to low density, high specific strength, good damping capacity and potential recycling capability [1, 2]. Therefore, $\mathrm{Mg}$ alloys have attracted attention of material researchers who strive to extend applications in engineering fields. Unfortunately, the high chemical activity of $\mathrm{Mg}$ alloys greatly limits their

Available online at http://link.springer.com/journal/40195

Zhi-Xin Ba

bzhx@njit.edu.cn

$凶$ Zhang-Zhong Wang

zzww@njit.edu.cn

1 School of Materials Science and Engineering, Nanjing Institute of Technology, Nanjing 211167, China

2 Jiangsu Key Laboratory of Advanced Structural Materials and Application Technology, Nanjing 211167, China widespread use in many applications [3-5]. To overcome this shortcoming, one of the effective ways to improve the corrosion resistance of $\mathrm{Mg}$ alloy is surface modification technology, including electroless plating [6], electroplating [7], chemical conversion [8-10], anodic oxidation [11], micro-arc anodic oxidation [12], sputtering [13] and ion implantation [14]. Chemical conversion coating has become a profound surface modification technology owing to low cost and concise preparation [15]. Nowadays, the $\mathrm{Mg}-\mathrm{Al}$ hydrotalcite (HT) film has attracted great attention as a chromate-free and environment-friendly coating [16-24]. The unique structure, potent adsorption and ionexchange capacity show superior corrosion resistance of the HT film [18, 23]. However, a few micro-cracks have been observed on the surface of $\mathrm{Mg}-\mathrm{Al} \mathrm{HT}$ film in previous studies [22-24]. As is known, if micro-cracks form conductive pathways of corrosive electrolytes, pitting corrosion will take place on the surface, and the pitting corrosion mode may lead to premature degeneration of mechanical integrity. Hence, the protection system with sealing ability becomes a very important and burning issue for the HT films. 
The sealing treatment techniques have been developed to modify the defects of protective coating and improve its integrity. Chromate compounds $\left(\mathrm{Cr}^{6+}\right)$ have been used as very effective and inexpensive corrosion inhibitors for sealing many protecting coatings, including anodic oxide coating, phosphate film and plasma electrolytic oxidation coating. However, it is recognized that chromating, being both highly toxic and carcinogenic, has led to worldwide researches to develop effective alternative sealing technologies [25].

It is well known that cerium oxides with the PillingBedworth ratio ( $\mathrm{P}-\mathrm{B}$ ratio) of more than 1 can reduce the porosity of coating [26]. Furthermore, cerium oxides with the higher dielectric parameter have a stable corrosion resistance [27]. So far, cerium conversion coatings (CeCCs) have been developed to meet the demand of nontoxic conversion coatings. Zhao et al. [25] reported sealed anodic oxidization film of aluminum alloy in cerium salt solution by pulse power. The results showed that the corrosion resistance of sealed micro-anodic film was comparable to that of the films sealed by potassium dichromate. Besides, sealing treatment technologies have been also applied to magnesium alloy. Mohedano et al. [28] developed Ce-based sealing post-treatment for plasma electrolytic oxidation (PEO) coatings on AM50 magnesium alloy, and the sealed PEO coatings showed higher corrosion resistance. These previous studies suggest that ceriumbased sealing treatment is a promising alternative to boiling and chromating sealing treatment [25, 29] owing to its low energy consumption, low toxicity and high efficiency. However, there were no reports about the relevant technologies of cerium-based sealing treatment for HT film.

The work aims to develop cerium-based sealing treatment for $\mathrm{Mg}-\mathrm{Al} \mathrm{HT}$ film on AZ91D Mg alloy to seal the micro-cracks of $\mathrm{Mg}-\mathrm{Al} \mathrm{HT}$ film and to provide a more effective and longer-term protection of $\mathrm{Mg}$ alloy from corrosion.

\section{Experimental}

\subsection{Materials}

The experimental materials were die-cast AZ91D $\mathrm{Mg}$ alloys with dimensions of $\Phi 15 \mathrm{~mm} \times 5 \mathrm{~mm}$. These samples were ground with metallographic sandpaper to 1500 grit and polished, then cleaned with anhydrous ethanol by ultrasonication for $5 \mathrm{~min}$ and washed ultrasonically with deionized water for $5 \mathrm{~min}$.

\subsection{Sample preparation}

The preparation of $\mathrm{Mg}-\mathrm{Al} \mathrm{HT}$ film was made according to Ref. [16]. Previous studies show that immersion method in carbonic acid solution $(\mathrm{pH} \sim 4.0)$ for $24 \mathrm{~h}$ is an available treatment to obtain $\mathrm{Mg}-\mathrm{Al} \mathrm{HT}$ films on $\mathrm{Mg}$ alloy.

Cerium-based sealing treatment was carried out in a Cecontaining solution $\left(\mathrm{Ce}\left(\mathrm{NO}_{3}\right)_{3}, 30 \mathrm{~g} / \mathrm{L}\right)$ in a water bath of $50{ }^{\circ} \mathrm{C}$. After sealing, treated samples were cleaned by deionized water and dried in cold air.

\subsection{Characterization}

The phase composition of the specimens was analyzed by X-ray diffraction (XRD, UltimaIV, Rigaku) with $\mathrm{Cu} K \alpha$ $(0.15405 \mathrm{~nm})$ radiation. The microstructure of the samples was studied by means of scanning electron microscopy (SEM, JSM-6360LV) equipped with an energy-dispersive $\mathrm{X}$-ray spectrum (EDS).

Electrochemical measurements including open circuit potential test (OCP), potentiodynamic polarization curve tests and electrochemical impedance spectroscopy measurements (EIS) were taken using an Ametek Parstat 2273 Potentiostat and powersuit system. A three-electrode cell was used with the sample as a working electrode, an $\mathrm{Ag}$ / $\mathrm{AgCl}$ reference electrode $(\mathrm{Ag} / \mathrm{AgCl}$ for $\mathrm{OCP})$ or saturated calomel electrode (SCE for potentiodynamic polarization curves and EIS) as a reference electrode, and a platinum plate as an auxiliary electrode. The area of the samples exposed to the solution was $1 \mathrm{~cm}^{2}$. OCP test was performed in $30 \mathrm{~g} / \mathrm{L} \mathrm{Ce}\left(\mathrm{NO}_{3}\right)_{3}$ solution. During cerium-based treatment, the value of OCP was recorded during the treatment process. Potentiodynamic polarization curve and EIS tests were performed in $0.1 \mathrm{~mol} / \mathrm{L} \mathrm{NaCl}$ solution. Potentiodynamic polarization curve tests were performed at a constant voltage scan rate of $3 \mathrm{mV} / \mathrm{s}$ after an initial immersion of $600 \mathrm{~s}$. EIS results were measured in the frequency range from $100 \mathrm{mHz}$ to $100 \mathrm{kHz}$ with $5 \mathrm{mV}$ ac amplitude with ten points per decade. ZSimpWin software was used to control and fit collected data.

Immersion tests were referred as ASTM G31-72. The ratio of the specimen surface area to solution volume was $1 \mathrm{~cm}^{2}: 60 \mathrm{~mL}$. The $0.1 \mathrm{~mol} / \mathrm{L} \mathrm{NaCl}$ solution was renewed every $24 \mathrm{~h}$, and the evolved hydrogen gas was collected by using a buret for quantitative evaluation of corrosion rate.

\section{Results and Discussion}

\subsection{Film Morphology}

Figure 1 shows the open circuit potential (OCP) of HT films as well as relevant morphologies during treatment in this work. Table 1 lists the chemical composition of the markers in Fig. 1 as obtained by EDS. As shown in Fig. 1, the sealing treatment undergoes three stages including nucleation, growth and fracture. Figure 1a-c corresponds 

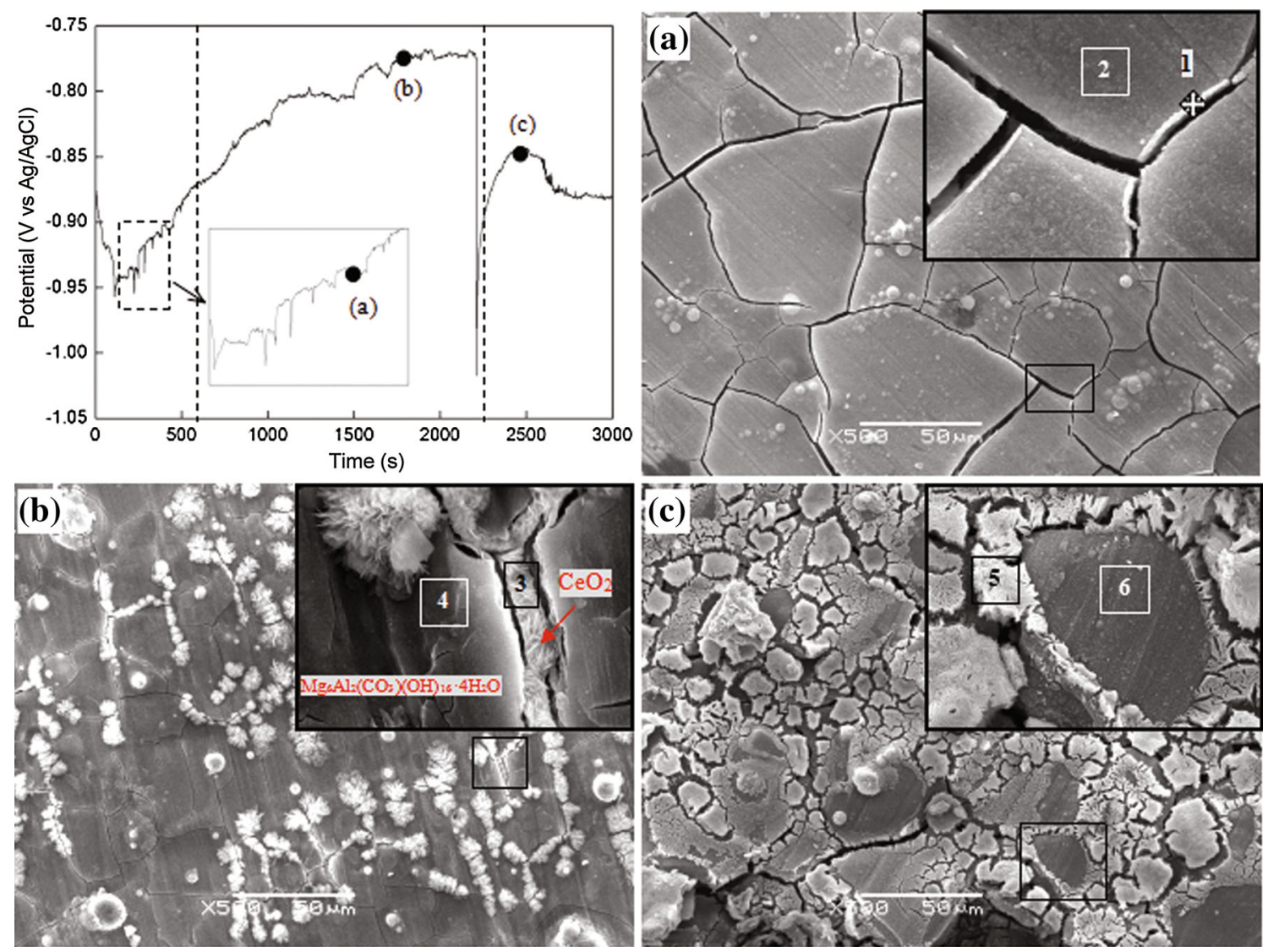

Fig. 1 OCP of HT films during cerium-based treatment as well as relevant morphologies: a nucleation, b growth, c cracking

Table 1 Compositions of the HT films treated for various periods of time

\begin{tabular}{llrlr}
\hline Regions & \multicolumn{4}{l}{ Elements (at.\%) } \\
\cline { 2 - 5 } & $\mathrm{Mg}$ & \multicolumn{1}{c}{$\mathrm{Al}$} & $\mathrm{O}$ & \multicolumn{1}{c}{$\mathrm{Ce}$} \\
\hline Region 1 in Fig. 1a & 17.64 & 6.50 & 46.75 & 29.11 \\
Region 2 in Fig. 1a & 40.51 & 19.41 & 37.46 & 2.62 \\
Region 3 in Fig. 1b & 11.03 & 3.52 & 49.49 & 35.96 \\
Region 4 in Fig. 1b & 36.02 & 20.12 & 40.29 & 3.57 \\
Region 5 in Fig. 1c & 30.49 & 11.79 & 42.21 & 15.51 \\
Region 6 in Fig. 1c & 37.53 & 18.11 & 40.41 & 3.95 \\
\hline
\end{tabular}

to relevant stages, respectively. At the stage of nucleation, there seems to be no changes in Fig. 1 compared with $\mathrm{Mg}-$ Al HT according to previous studies [16, 22]. However, the value of OCP rapidly decreases, which might be due to acid Ce-containing solution contacting with $\mathrm{Mg}$ matrix through micro-cracks. Then, OCP increases with fluctuations. Sudden decline may represent the dissolution of exposed $\mathrm{Mg}$ matrix; hence, rising is related to a nucleation of CeCCs [4]. At this stage, white particles in Region 1, enriched in Ce element and identified by EDS, are mostly observed on the micro-cracks, which reflects that white particles, defined as CeCCs, are preferentially nucleated in micro-cracks. At the second stage, based on the nucleus, CeCCs gradually grow up; accordingly, the value of OCP increases and then stabilizes little by little. As shown in Fig. 1b, when being treated for 30 min, many continuous cotton-shaped depositions, enriched in $\mathrm{Ce}$ element in Region 3, formed in the micro-cracks. Figure 2 shows the $\mathrm{XRD}$ pattern of the film in this stage. $\mathrm{X}$-ray peaks of $\mathrm{Mg}-$ Al hydrotalcite $\left(\mathrm{Mg}_{6} \mathrm{Al}_{2}(\mathrm{OH})_{16} \mathrm{CO}_{3} \cdot 4 \mathrm{H}_{2} \mathrm{O}\right)$ (JCPDS No. 41-1428) and cerium dioxide $\left(\mathrm{CeO}_{2}\right)$ (JCPDS No. 34-0394) are observed after micro-cracks are sealed, exhibiting that the $\mathrm{CeCCs}$ are composed of $\mathrm{CeO}_{2}$ [30]. After being sealed, $\mathrm{CeCCs}$ are gradually deposited on the surface. With a sudden drop in the value of OCP, CeCCs in the microcracks are broken up in Region 5 [31], and the microcracks reappear as shown in Fig. 1c. These results exhibit that HT film is sealed when immersed in $\mathrm{Ce}\left(\mathrm{NO}_{3}\right)_{3}$ solution for $30 \mathrm{~min}$.

\subsection{Corrosion Resistance}

Polarization curves are demonstrated in Fig. 3. There is a great difference at the anodic sides of the two curves. The anodic side of the sealed HT-coated sample exhibits a 


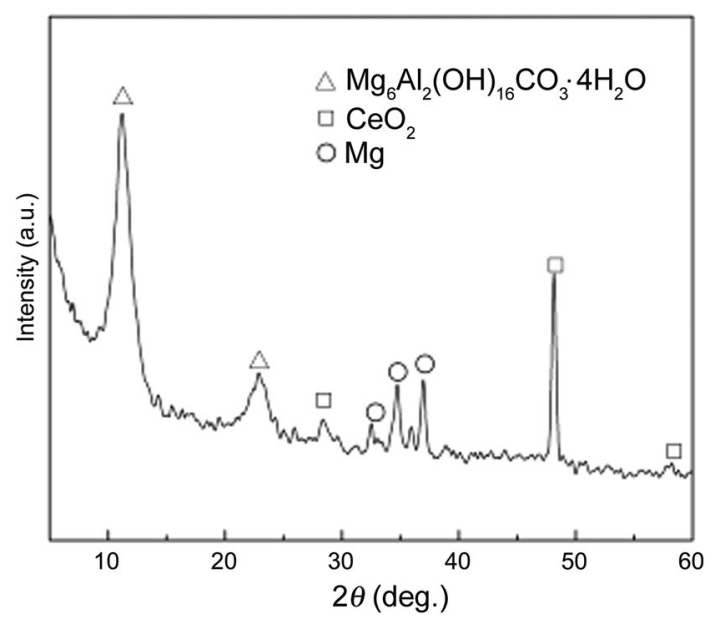

Fig. 2 XRD pattern of the film on $\mathrm{Mg}$ alloy treated for $30 \mathrm{~min}$

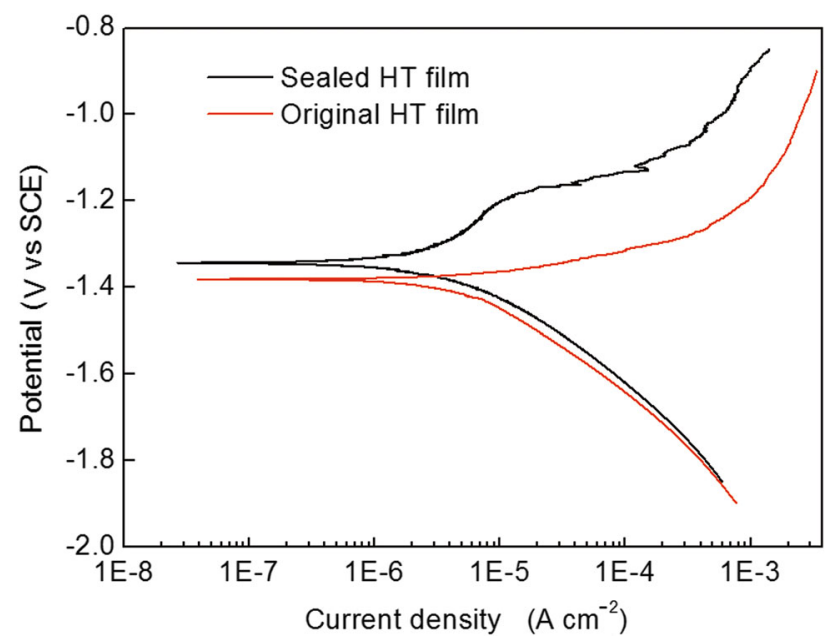

Fig. 3 Polarization curves of samples in $0.1 \mathrm{~mol} / \mathrm{L} \mathrm{NaCl}$ solution

passive region, and the breakdown potential $\varphi_{\mathrm{b}}$ is about $-1.172 \mathrm{~V}$ (vs SCE). However, without passive region, the original HT-coated sample is corroded quickly after reaching corrosion potential. Besides, the polarization curve of sealed HT-coated sample does not exhibit the Tafel region, and the corrosion current density $\left(J_{\text {corr }}\right)$ is determined by the extrapolation of the cathodic Tafel line to the corrosion potential $(\varphi)$ [32], as shown in Fig. 3. The $J_{\text {corr }}$ of the sealed HT film $\left(5.041 \mu \mathrm{A} / \mathrm{cm}^{2}\right)$ is lower than that of the original HT film $\left(14.95 \mu \mathrm{A} / \mathrm{cm}^{2}\right)$, and the $\varphi_{\text {corr }}$ of the sample increases from $-1.392 \mathrm{~V}$ (vs SCE) for original HT film to $-1.332 \mathrm{~V}$ (vs SCE) for sealed HT film, exhibiting that sealing treatment contributes to slowing down the corrosion rate of $\mathrm{Mg}$ alloy.

In order to further investigate long-term corrosion resistance of sealed HT film, hydrogen evolution curves are observed in Fig. 4. The hydrogen evolution volume of the

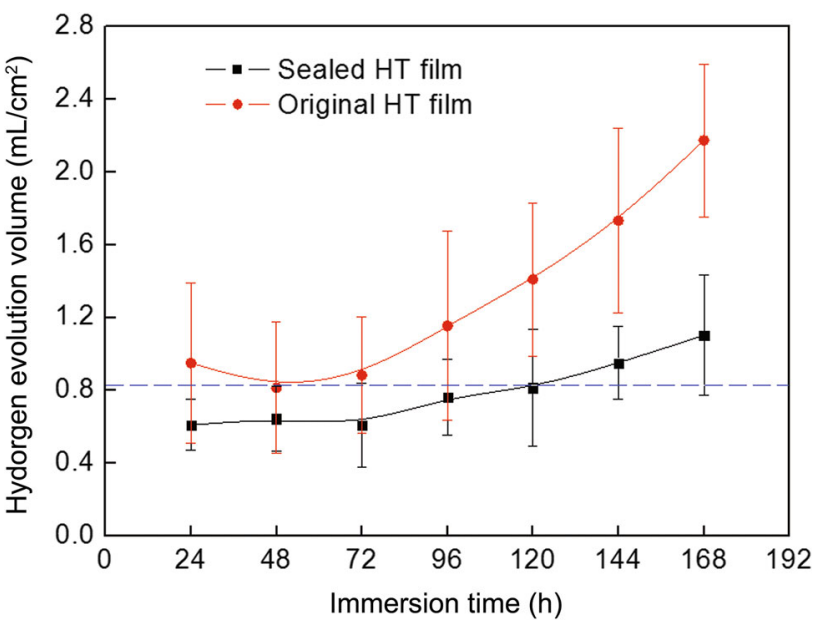

Fig. 4 Hydrogen evolution curves immersed in $0.1 \mathrm{~mol} / \mathrm{L} \mathrm{NaCl}$ solution

sealed HT film is less than that of original HT film, indicating that sealing treatment can slow down corrosion rate. During immersion tests for $120 \mathrm{~h}$, sealed HT-coated sample keeps a lower hydrogen evolution rate than the minimal one for original HT-coated sample, showing that sealing treatment provides an effective protection for $\mathrm{Mg}$ alloy with micro-cracks sealed. When being immersed for $168 \mathrm{~h}$, the hydrogen evolution volume of sealed HT-coated sample exceeds the minimum value for original HT-coated sample, which exhibits that sealing effect becomes weaker owing to longtime immersion in corrosive solution.

Figure 5 shows macro- and micro-corrosion morphologies of samples immersed in $0.1 \mathrm{~mol} / \mathrm{L} \mathrm{NaCl}$ solution. When immersed for $120 \mathrm{~h}$, the surface of the sample coated with sealed HT film is smooth and uniform (Fig. 5b), while original HT-coated sample is covered with numerous pits (Fig. 5a), in which case there are fewer micro-cracks appearing on the sealed HT film after 120-h immersion (Fig. 5e), and the size of micro-cracks is much smaller than that of original HT film (Fig. 5d). However, when being immersed for 168 h, pits appear as shown in Fig. 5c. Figure $5 \mathrm{f}$ exhibits that, with immersion for $168 \mathrm{~h}$, the size of micro-cracks increases and the sealing effect gradually wears off, demonstrating that hydrogen evolution rate of immersion of $168 \mathrm{~h}$ exceeds the minimum one for original HT film according to Fig. 4.

The EIS tests were taken to monitor the changes in corrosion behavior [4]. Figure 6 shows the EIS spectra of the AZ91D alloy coated with original HT film and sealed HT film exposed to $0.1 \mathrm{~mol} / \mathrm{L} \mathrm{NaCl}$ solution for various periods of time. The electrochemical behavior of the sealed HT film undergoes a series of variations during immersion tests with Nyquist plots changing. Before immersion, the Nyquist plot for sealed HT film consists of one high- 

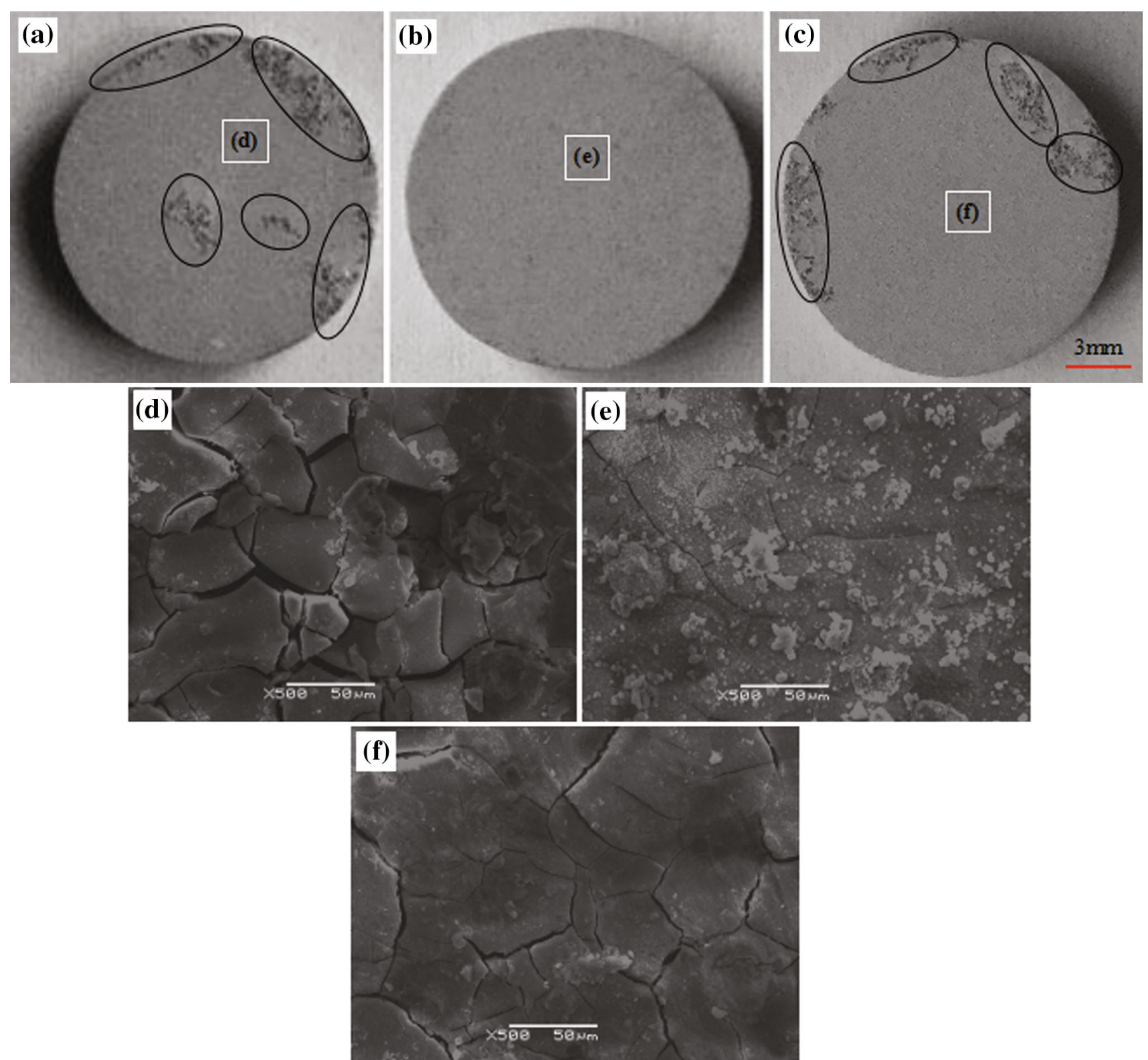

Fig. 5 Macro- and micro-corrosion morphologies of the samples immersed in $0.1 \mathrm{~mol} / \mathrm{L} \mathrm{NaCl}$ solution: macro-corrosion morphologies: a original HT-120 h, b sealed HT-120 h, c sealed HT-168 h; micro-corrosion morphologies: d original HT-120 h, e sealed HT-120 h, f sealed HT-168 h
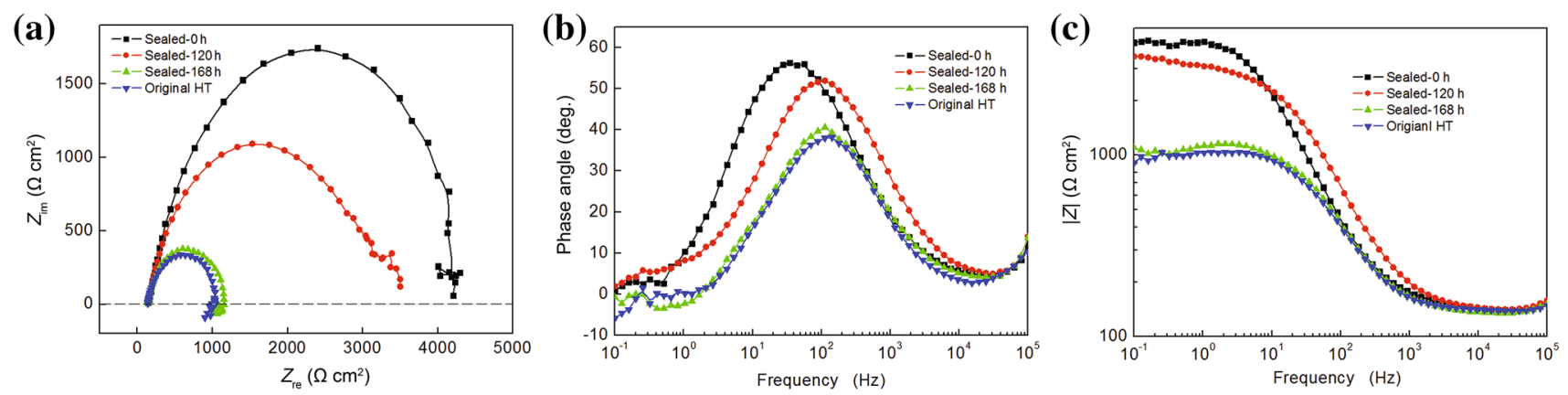

Fig. 6 EIS spectra of the AZ91D alloys immersed in $0.1 \mathrm{~mol} / \mathrm{L} \mathrm{NaCl}$ solution. a Nyquist plots, b, $\mathbf{c}$ bode plots 
frequency capacitive loop, one medium-frequency capacitive loop and one low-frequency capacitive loop, and there are three time constants in Fig. 6b. The high-frequency capacitance loop is due to the solution resistance, the medium-frequency capacitive loop relates to the sealed HT film, and the low-frequency capacitive loop is owing to the reaction between the film and $\mathrm{Mg}$ alloy substrate. With increasing immersion time to $120 \mathrm{~h}$, the diameter of the plot decreases (shown in Fig. 6a) and the $|Z|$ value changes from $4.3 \times 10^{3}$ to $3.5 \times 10^{3} \Omega \mathrm{cm}^{2}$ (shown in Fig. $6 \mathrm{c}$ ). Higher $|Z|$ value represents better corrosion resistance [33]. When being immersed for $168 \mathrm{~h}$, the diameter of the plot has the same size as that of original HT film and the $|Z|$ value is only $1.1 \times 10^{3} \Omega \mathrm{cm}^{2}$. Besides, the low-frequency inductance loop emerges, implying the initiation of pitting corrosion.

As shown in Fig. 7, equivalent circuits are used to fit the experimental data of EIS plots. The data of fitting results are listed in Table 2. $R_{s}$ represents the solution resistance. The $R_{f}$ value with a $Q_{f}$ corresponds to the resistance of film. $R_{c t}$ and $C_{d l}$ represent the charge-transfer resistance and electric double-layer capacity at the interface between film and substrate, respectively. The inductive behavior of the sample coated with original HT film is represented by the resistance $R_{L}$ and inductance $L$, implying that the initiation of pitting corrosion is owing to wider micro-cracks when sealed HT-coated sample is immersed for $168 \mathrm{~h}$. With increasing immersion time, the $R_{\mathrm{f}}$ for the sealed HT-coated sample gradually reduces. A constant-phase element $(Q)$ is

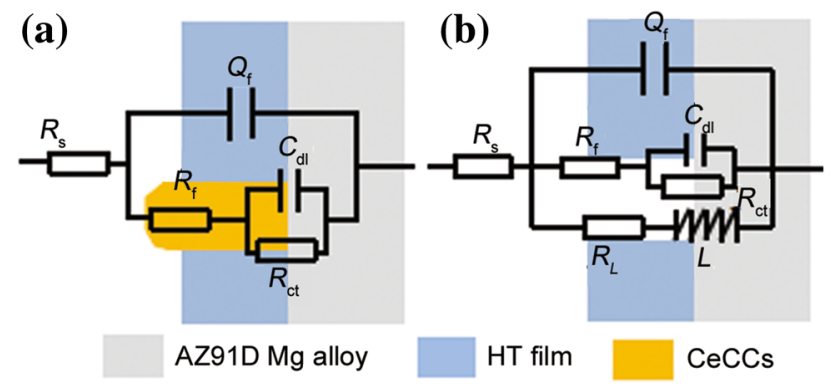

Fig. 7 Equivalent circuits for the EIS spectra of AZ91D alloys immersed in $0.1 \mathrm{~mol} / \mathrm{L} \mathrm{NaCl}$ solution: a sealed HT film for $0-120 \mathrm{~h}$, b sealed HT film immersed for more than $168 \mathrm{~h}$ and original HT film defined by $Y_{0}$ and $n\left(Z_{Q}=1 / Y_{0} \cdot(j w)^{-n}, 0<n<1\right)$. If $n$ is equal to $1, Q$ is identical to a capacitor. If the value of $n$ is $0, Q$ is equivalent to a resistance [34]. The $Q$ changes along with $\mathrm{n}$ decreasing from 0.8311 to 0.6861 , reflecting that the integrity of the film is destroyed during immersion in $\mathrm{NaCl}$ solution [34]. Besides, a resistance $R_{L}$ as well as inductance $L$ emerges in accordance with the micro-cracks in Fig. $7 \mathrm{~b}$ when being immersed for $168 \mathrm{~h}$, demonstrating that sealing effect of $\mathrm{CeO}_{2}$ becomes weaker, and the micro-cracks of HT film reappear. This result is in accordance with Fig. 5.

\subsection{Mechanism of Sealing Process}

Figure 8 shows a schematic diagram of the coating formation mechanism. According to the SEM observation shown in Fig. 1, it can be proposed that the treatment process is considered as three stages.

In the nucleation stage, the Mg substrate is exposed in $\mathrm{Ce}$-containing solution through micro-cracks. Then, the $\mathrm{Mg}$ substrate dissolves and reacts with the electrolyte solution, with hydrogen gas bubble evolution. In addition, with the increase of $\mathrm{pH}$ in the micro-cracks owing to hydrogen gas bubbles evolution, the particles of $\mathrm{CeO}_{2}$ are deposited in the micro-cracks, according to the reactions as follows [35]:

$$
\begin{aligned}
& 6 \mathrm{H}^{+}+2 \mathrm{Ce}^{3+}+2 \mathrm{Mg} \rightarrow 2 \mathrm{Ce}^{4+}+2 \mathrm{Mg}^{2+}+3 \mathrm{H}_{2} \uparrow \\
& \mathrm{Ce}^{4+}+4 \mathrm{OH}^{-} \rightarrow \mathrm{CeO}_{2} \downarrow+2 \mathrm{H}_{2} \mathrm{O} .
\end{aligned}
$$

With increasing treatment time, based on the nucleation, the deposition amount of $\mathrm{CeO}_{2}$ increases. Herein, the treatment process comes into the growth stage. With decreasing the size of micro-cracks, the dissolution rate of $\mathrm{Mg}$ substrate slows down. $\mathrm{Ce}^{3+}$ ions are oxidized, hydrogen gas bubbles evolve, and the deposition amount of $\mathrm{CeO}_{2}$ increases, which are the main reactions as follows [35]:

$$
\begin{aligned}
& 2 \mathrm{H}^{+}+2 \mathrm{Ce}^{3+} \rightarrow 2 \mathrm{Ce}^{4+}+\mathrm{H}_{2} \uparrow \\
& \mathrm{Ce}^{4+}+4 \mathrm{OH}^{-} \rightarrow \mathrm{CeO}_{2} \downarrow+2 \mathrm{H}_{2} \mathrm{O} .
\end{aligned}
$$

At the growth stage, the micro-cracks are sealed by $\mathrm{CeO}_{2}$ when being treated for $30 \mathrm{~min}$. Then, with microcracks sealed, the volume of hydrogen gas accumulates in

Table 2 Fitting results of EIS plots for AZ91D Mg alloys

\begin{tabular}{lllllllll}
\hline Sample & $R_{s}\left(\Omega \mathrm{cm}^{2}\right)$ & $R_{f}\left(\Omega \mathrm{cm}^{2}\right)$ & $Y_{0}\left(\mu \Omega^{-1} \mathrm{~cm}^{-2} / \mathrm{s}\right)$ & $n$ & $C_{d l}\left(\mu \mathrm{F} / \mathrm{cm}^{2}\right)$ & $R_{c t}\left(\Omega \mathrm{cm}^{2}\right)$ & $R_{L}\left(\Omega \mathrm{cm}^{2}\right)$ & $L(\mathrm{H} \mathrm{cm})$ \\
\hline Sealed-0 h & 141.8 & 4054.0 & 8.891 & 0.8311 & 1.736 & 124.0 & - & - \\
Sealed-120 h & 140.3 & 2995.0 & 7.361 & 0.7869 & 0.9349 & 112.0 & - \\
Sealed-168 h & 141.3 & 979.7 & 22.72 & 0.6861 & 2.247 & 112.7 & 910.3 \\
Original HT & 142.0 & 827.6 & 21.01 & 0.7058 & 2.475 & 121.4 & 1441 \\
\hline
\end{tabular}




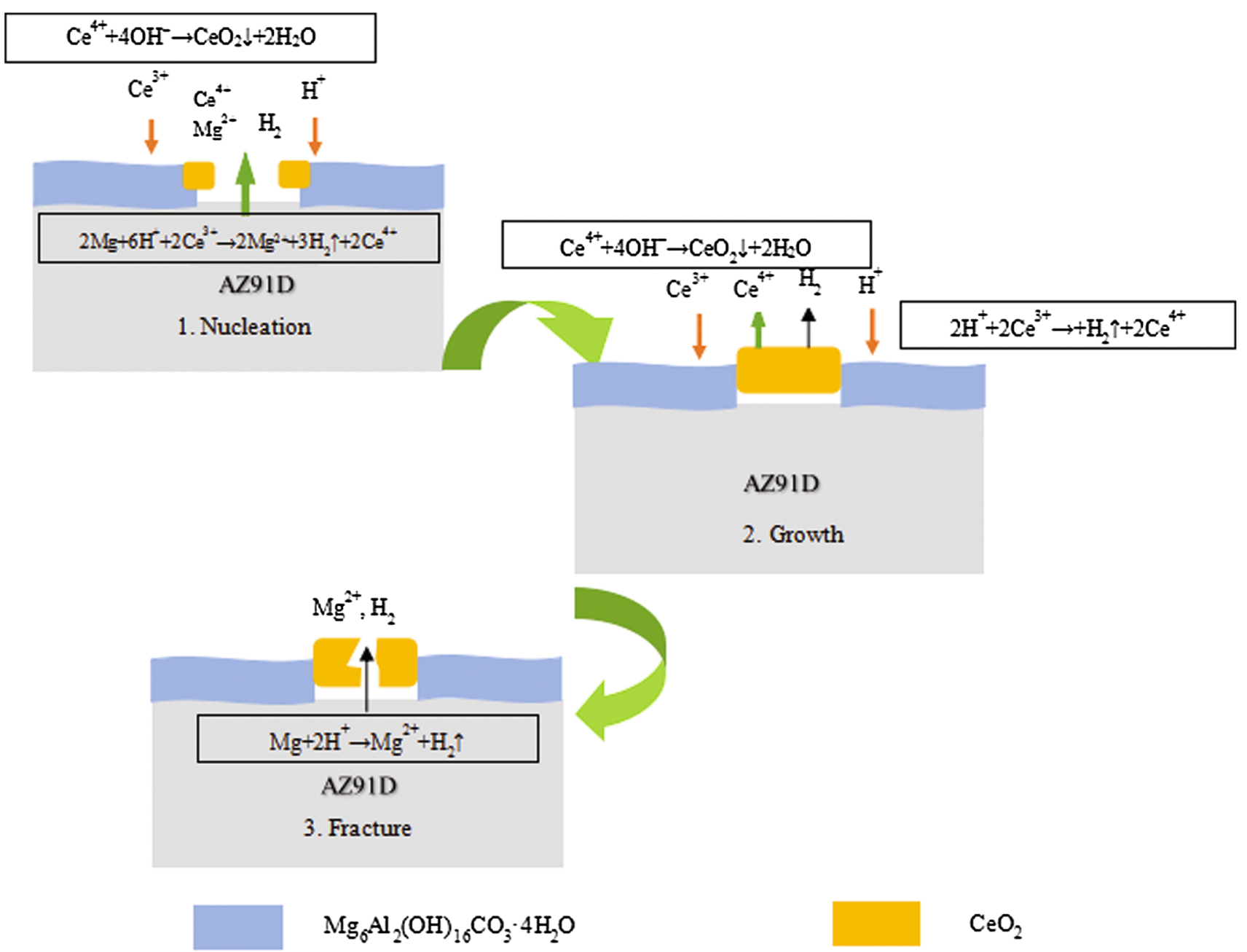

Fig. 8 Schematic diagram of possible treatment process in Ce-containing solution

the micro-cracks owing to residual acid Ce-containing solution in the first stage. Once enough hydrogen gas accumulates, CeCCs will be broken up as shown in Fig. 8 . The third stage is defined as the fracture stage.

\section{Conclusions}

1. Cerium-based sealing treatment was successfully developed on $\mathrm{Mg}-\mathrm{Al}$ hydrotalcite (HT) film of AZ91D $\mathrm{Mg}$ alloy. Cerium-based treatment experienced three stages including nucleation, growth and fracture.

2. With immersion for $30 \mathrm{~min}$ in $30 \mathrm{~g} / \mathrm{L} \mathrm{Ce}\left(\mathrm{NO}_{3}\right)_{3}$ solution, cerium-based treatment had a good sealing effect on $\mathrm{Mg}-\mathrm{Al}$ HT film. Micro-cracks of $\mathrm{Mg}-\mathrm{Al} \mathrm{HT}$ film were sealed by CeCCs, composed of $\mathrm{CeO}_{2}$.

3. Cerium-based sealing treatment increased the corrosion potential $\left(\varphi_{\text {corr }}\right)$ and decreased the corrosion current density $\left(J_{\text {corr }}\right)$ of HT film sample. Besides, the

\begin{abstract}
hydrogen evolution rate of sealed HT-coated sample was lower than that original HT sample. Sealing effect of cerium-based treatment gradually faded away with increasing immersion time. When being immersed for $168 \mathrm{~h}$, sealed HT film had nearly the same corrosion resistance as original HT film, exhibiting that sealed HT film provided higher efficiency and longer-term protection of $\mathrm{Mg}$ alloy from corrosion.
\end{abstract}

Acknowledgments This work was supported by the Jiangsu Key Laboratory of Advanced Structural Materials and Application Technology (No. ASMA201407), the Innovative Foundation Project for Students of Jiangsu Province (No. 201511276012Z) and the Innovative Foundation Project for Students of Nanjing Institute of Technology (No. TB201617004).

\section{References}

[1] W.Q. Xu, N. Birbili, G. Sha, Y. Wang, J. Daniels, Y. Xiao, M. Ferry, Nat. Mater. 14, 1229 (2015) 
[2] L. Pezzato, K. Brunelli, E. Napolitani, M. Magrini, M. Dabalà, Appl. Surf. Sci. 357, 1031 (2015)

[3] R.C. Zeng, L.J. Liu, T.T. Pang, F. Zhang, W.W. Zhang, S.Q. Li, H.Z. Cui, E.H. Han, Acta Metall. Sin. (Engl. Lett.) 28, 373 (2015)

[4] R.Q. Hou, C.Q. Ye, C.D. Chen, S.G. Dong, M.Q. Lv, S. Zhang, J.S. Pan, G.L. Song, C.J. Lin, Acta Metall. Sin. (Engl. Lett.) 29, 46 (2016)

[5] X.M. Zong, D. Wang, W. Liu, K.B. Nie, C.X. Xu, J.S. Zhang, Acta Metall. Sin. (Engl. Lett.) 29, 32 (2016)

[6] D. Seifzadeh, Z. Rajabalizadeh, Surf. Coat. Technol. 218, 119 (2013)

[7] J. Tang, K. Azumi, Surf. Coat. Technol. 205, 3050 (2011)

[8] J.L. Wang, P. Wang, Y.C. Guo, J.P. Li, Rare Metal Mater. Eng. 43, 1397 (2014)

[9] H.F. Gao, H.Q. Tan, J. Li, Y.Q. Wang, J.Q. Xun, Surf. Coat. Technol. 212, 32 (2012)

[10] G. Jin, Y. Yang, X. Cui, Q. Li, Mater. Lett. 65, 1145 (2011)

[11] X.B. Chen, X. Zhou, T.B. Abbott, M.A. Easton, N. Birbilis, Surf. Coat. Technol. 217, 147 (2013)

[12] Y. Wang, D.B. Wei, J. Yu, S.C. Di, J. Mater. Sci. Technol. 30, 984 (2014)

[13] R. Kotoka, S. Yarmolenko, D. Pai, S.C. Di, J. Mater. Sci. Technol. 31, 873 (2015)

[14] Z.Z. Wang, X.W. Tao, X.B. Zhang, Z.X. Ba, Q. Wang, Mater. Technol. Adv. Perform. Mater. 30, 321 (2015)

[15] R.K. Gupta, K. Mensah-Darkwa, D. Kumar, J. Mater. Sci. Technol. 30, 47 (2014)

[16] J.K. Lin, C.L. Hsia, J.Y. Uan, Scr. Mater. 56(11), 927 (2007)

[17] J. Chen, Y.W. Song, D.Y. Shan, E.H. Han, Corros. Sci. 63, 148 (2012)

[18] J.K. Lin, J.Y. Uan, Corros. Sci. 51, 1181 (2009)
[19] J. Chen, Y.W. Song, D.Y. Shan, E.H. Han, Corros. Sci. 93, 90 (2015)

[20] J. Chen, Y.W. Song, D.Y. Shan, E.H. Han, Trans. Nonferrous Met. Soc. China 21, 936 (2011)

[21] R.C. Zeng, Z. Liu, F. Zhang, S.Q. Li, Q.K. He, H.Z. Cui, E.H. Han, Trans. Nonferrous Met. Soc. China 25, 1917 (2015)

[22] Z.X. Ba, X.B. Zhang, Z.Z. Wang, Q.S. Dong, Q. Wang, Trans. Nonferrous Met. Soc. China 24, 3818 (2014)

[23] J. Chen, Y.W. Song, D.Y. Shan, E.H. Han, Corros. Sci. 74, 130 (2013)

[24] J. Chen, Y.W. Song, D.Y. Shan, E.H. Han, J. Mater. Sci. Technol. 31, 384 (2015)

[25] X.H. Zhao, Y. Zuo, J.M. Zhao, Corros. Prot. 27, 400 (2006)

[26] J.S. Cai, F.H. Cao, L.R. Chang, J.J. Zheng, J.Q. Zhang, C.N. Cao, Appl. Surf. Sci. 257, 3804 (2011)

[27] S. Niroumandrad, M. Rostami, B. Ramezanzadeh, Appl. Surf. Sci. 357, 2121 (2015)

[28] M. Mohedano, C. Blawert, M.L. Zheludkevich, Surf. Coat. Technol. 269, 145 (2015)

[29] X.W. Yu, C.N. Cao, Thin Solid Films 423, 252 (2003)

[30] Y.L. Lee, F.J. Chen, C.S. Lin, J. Electrochem. Soc. 160, C28 (2012)

[31] V. Bertagna, R. Erre, F. Rouelle, D. Lévy, S. Petitdidier, M. Chemla, J. Solid State Electrochem. 5, 306 (2001)

[32] A. Robin, G. Silva, J.L. Rosa, Mater. Res. 16, 1254 (2013)

[33] C.N. Cao, J.Q. Zhang, Introduction of Electrochemical Impedance Spectroscopy, 1st edn. (Science Press, Beijing, 2002), pp. 151-191

[34] Z.X. Ba, Q.S. Dong, X.B. Zhang, J.X. Wang, C. Yuan, Y.M. Liao, Surf. Coat. Technol. 294, 67 (2016)

[35] Y.L. Lee, Y.R. Chu, F.J. Chen, C.S. Lin, Appl. Surf. Sci. 276, 578 (2013) 